\title{
Exploring the Impact of Openness on Inflation in Taiwan: Mediation Analysis With A Quantile Approach
}

\author{
TZU-KUANG HSU \\ Department of Business Administration \\ Chung Hua University \\ No.707, Sec.2 WuFu Rd., \\ Hsinchu, \\ TAIWAN, R.O.C.
}

\begin{abstract}
This paper adopts an innovative method, which is totally different from the past research studies, combining mediation analysis and a quantile regression to examine the impact of openness on inflation whether through money supply or not from 1961 to 2019 in Taiwan. The result of the traditional ordinary least square approach shows that Taiwan's trade openness affects inflation through the full mediation effect of money supply for the period of 1961-2019 and there is no direct relation between trade openness and inflation. However, the results of this innovative approach indicate that Taiwan's trade openness affects inflation through the partial mediation effect of money supply at 0.3 and 0.5 distributions of inflation. This result indicates that trade openness not only does directly affect inflation, but also indirectly affects inflation through the money supply.
\end{abstract}

Key-Words: A quantile Approach, Inflation, Mediation Analysis, Openness.

Received: November 23, 2019. Revised: March 31, 2020. Accepted: April 6, 2020. Published: April 10, 2020.

\section{Introduction}

Nobel Laureate Milton Friedman in 1963 asserted that inflation is always and everywhere a monetary phenomenon. In other words, a continuing and rapid rise in the general price level must be driven by a continually increasing money supply. Many empirical literatures have confirmed this proposition (Yang [19], Parikh [13], Beltas and Jones [2], Cheng [3], and Karras [7]).

However, the open macroeconomic theory states that the effects of the money supply on the price level depend on the economy's openness. In other words, the inflationary effects of changes in the money supply increase with openness. Karras [7] has presented evidence that the more open the economy, the larger inflation effects of a given change in the money supply for 38 countries. On the other hand, some researchers suggest that there is a direct relation between trade openness and inflation. For example, Romer [16] thinks that trade openness would act as a brake to the gains obtained by the inflationary surprise. Thus, more open countries would have fewer incentives to generate inflation. Lane [12] proposes another explanation about the relation between openness and inflation. He thinks that this proposition happens because of the existence of imperfect competition and the presence of rigid nominal prices in the nontradable sector. Besides, Terra [18] argues that the negative relation between openness and inflation is mainly because of heavily indebted countries during the debt crisis period. Many empirical literatures have also confirmed this direct relation (Gruben and McLeod [4], Sachsida, Carneiro, and Loureiro [17], and Gruben and McLeod [5]). In particular, Kim and Beladi [8] find that there is the directly negative openness-inflation relation for developing countries and a positive relation for advanced economies.

The purpose of this paper is to investigate either if there is the inflationary effects of increasing in the money supply with the openness of the Taiwan's economy, or if there is the direct relationship from openness to inflation in Taiwan, or if there exist both direct and indirect relationship. Moreover, in this study we use an innovative methodology which 
is totally different from the past research studies. We combine mediation analysis and a quantile regression which proposed Koenker and Bassett [9] to investigate the dynamic shortrun causal impact of openness on inflation across different conditional inflation from 1961 to 2019 in Taiwan. The advantage of using this quantile regression is that a quantile regression will be more robust (Koenker, [11]) because it estimates the median and the full range of other conditions, rather than ordinary least squares (OLS) regression to estimate mean.

This paper is organized as follows. In sectionS II and III, we present and discuss the standard open macroeconomic model and methodology. Section IV reports data collection and empirical results. Section V provides the conclusions.

\section{Open Macroeconomic Model}

Taken from Karras [7] paper, we establish the standard open economy version of the aggregate demand and aggregate supply model as follows.

$$
\begin{aligned}
& y=-\alpha\left(e+p-p^{*}\right)-\phi\left(i-\pi^{e}\right)+\beta y^{*} \\
& m-p=k y-f i \\
& y=-g(w-p) \\
& w=\sigma q \\
& q=(1-\delta) p+\delta\left(p^{*}-e\right) \\
& i=i^{*}-\varepsilon^{e} \\
& \varepsilon^{e}=\left(\pi^{*}\right)^{e}-\pi^{e}
\end{aligned}
$$

Equations 1 and 2 are the standard open economy version of the IS and LM, respectively. Equation 1 implies that expenditure on domestic goods is decreasing in the real exchange rate and the real interest rate, and increasing in foreign income. The variable $y$ is real GDP, e is the exchange rate, $p$ is the GDP deflator, $\mathrm{i}$ is the interest rate, $\pi^{e}$ is the expected inflation rate, asterisks denote variables for the rest of the world, and $\alpha, \phi, \beta$ are non-negative parameters. Equation 2 implies that real money demand is increasing in income and decreasing in the nominal interest rate. The variable $\mathrm{m}$ is the money supply, and $\mathrm{k}$ and $\mathrm{f}$ are non-negative parameters.

Equation 3 is the aggregate supply which implied by a negatively sloping labor demand curve and a short-run production function. The variable $\mathrm{w}$ is the wage, and $\mathrm{g}$ is a non-negative parameter. Equation 4 is a wage-indexation equation. The variable $\mathrm{q}$ is the CPI, and $\sigma$ is the degree of indexation to the CPI.

Equation 5 defines the CPI as a weighted average of domestic and foreign price levels. The parameter $\delta$ is non-negative and can be thought of as a measure of the economy's openness. Equation 6 defines the interest rate parity. The variable $\varepsilon^{e}$ is the expected appreciation rate. Equation 7 is the relative version of purchasing power parity. All variables are logarithms except the interest rate and inflation rate.

Combining equations 3, 4 and 5, aggregate supply can be written as below.

$$
y=g[1-\sigma(1-\delta)] p+\delta g \sigma\left(e-p^{*}\right)
$$

Substituting from equations 6 and 7, and totally differentiating the equations 1,2 and 8, we obtain the following matrix:

$$
\left[\begin{array}{ccc}
1 & \alpha & \alpha \\
k & 0 & 1 \\
1 & -\sigma g \delta & -g[1-\sigma(1-\delta)]
\end{array}\right]\left[\begin{array}{l}
d y \\
d e \\
d p
\end{array}\right]=\left[\begin{array}{c}
0 \\
1-f \varepsilon_{m}^{e} \\
0
\end{array}\right] d m
$$

where $\varepsilon_{m}^{e}=\partial \varepsilon^{e} / \partial m<0$

Solving equation 9, the steady-state effects of monetary policy on output, prices and the exchange rate are given by $d y / d m=\left(1-f \varepsilon_{m}^{e}\right)[\alpha g(1-\sigma)] /|D|$

$$
d p / d m=\left(1-f \varepsilon_{m}^{e}\right)(\sigma g \delta+\alpha) /|D|
$$




$$
d e / d m=-\left(1-f_{\varepsilon_{m}}^{e}\right)[g(1-\sigma)+\sigma g \delta+\alpha] /|D|
$$

where $|D|=\alpha+\alpha k g(1-\sigma)+\sigma g \delta>0$

From equation 11, we can predict that the price effect of monetary policy depends on the openness of the economy, as measure by $\delta$. Here money supply is like a mediation which refers to the transmission of the effect of an independent variable on a dependent variable through it.

However, as in Romer [16] paper, we establish the direct relation between openness and inflation as follows.

$$
\operatorname{INFLATION}=\mathrm{a}_{0}+\mathrm{a}_{1} \mathrm{OPEN}+\mathrm{e}_{0}
$$

Here, the $\log$ of inflation (INFLATION) is the natural logarithm of the implicit GDP deflator. The degree of openness (OPEN) is measured as the rate of imports in relation to Gross domestic product (GDP). Technically, e 0 is the stochastic error term.

\section{Methodology}

\subsection{Meditation Analysis on Money Supply}

We can use mediation analysis to investigate the causality from openness to inflation through money supply in equation 11 and the direct relation between openness and inflation in equation 13. The most common approach to examine mediation effect is the causal steps procedure popularized by Baron and Kenny [1]. This analysis involves the following set of regression equations relating the independent variable, mediator variable, and dependent variable:

INFLATION $=\mathrm{b}_{0}+\mathrm{b}_{1}$ OPEN $+\mathrm{e}_{1}$ (14)

$\mathrm{MONEY}=\mathrm{c}_{0}+\mathrm{c}_{1} \mathrm{OPEN}+\mathrm{e}_{2}$

INFLATION $=\mathrm{d}_{0}+\mathrm{d}_{1}$ OPEN

$$
+\mathrm{d}_{2} \mathrm{MONEY}+\mathrm{e}_{3}
$$

Here, OPEN and INFLATION variables are measured as in equation 13. Money supply (MONEY) is measured as the M2, which includes currency held outside banks, demand deposits, time deposits, and quasi money. Meditation analysis on money supply processes are as follows:

Step 1: The independent variable OPEN should relate to the dependent variable INFLATION, such that $b_{1}$ in Equation 14 is significant. This condition is used to establish that there is a relationship between OPEN and INFLATION to be mediated.

Step 2: The independent variable OPEN should relate to the mediator variable MONEY, such that $\mathrm{c}_{1}$ in Equation 15 is significant. This condition establishes the first stage of the mediated effect.

Step 3: The mediator variable MONEY should relate to the dependent variable INFLATION, such that $\mathrm{d}_{2}$ in Equation 16 is significant. This condition establishes the second stage of the mediated effect.

Step 4: The independent variable OPEN should no longer relate to the dependent variable INFLATION after the mediator variable MONEY is controlled, such that $d_{1}$ in Equation 16 is not significant. This condition shows that the relationship between OPEN and INFLATION examined under the first condition disappears when the mediated effect transmitted through MONEY is taken into account.

Satisfying all four steps provides evidence for complete mediation, whereas satisfying the first three steps indicates partial mediation if $d_{1}$ in Equation 16 is still significant and is smaller than $b_{1}$ in Equation 14.

\subsection{A Quantile Regression}

A quantile regression is a statistical technique intended to estimate and conduct inference about conditional quantile function. Koenker and Bassett [9] proposed the quantile regression 
approach as an alternative to least squares regression in a wide range of applications. This approach takes into consideration the skewness of the distribution and gives a more complete picture of the performance that is affected by the various independent variables. This technique was further developed by Koenker and Hallock [10] and Koenker [11].

According to Koenker [11], a quantile regression is used when an estimate of the various quantile of a population is desired. One advantage of using a quantile regression to estimate the median and the full range of other conditions, rather than ordinary least squares regression to estimate mean, is that a quantile regression will be more robust in response to large outliers. Like the least absolute deviations, the quantile regression objective function is a weighted sum of absolute deviations, which gives a robust measure of location, so that the estimated coefficient vector is not sensitive to outlier observations on the dependent variable. In addition, it also provides a more efficient approach than the least square method when the error term is non-normal.

A quantile regression can be seen as a natural analogue in regression analysis to the practice of using different measures of central tendency and statistical dispersion to obtain a more comprehensive and robust analysis. Another advantage of a quantile regression is the fact that any quantile can be estimated.

According to Koenker and Bassett [9] method, we let $\left\{y_{t}, t=1,2 \ldots, T\right\}$ be a random sample on the regression process $y_{t}=u_{t}+x_{t} \beta$, having conditional distribution function $F_{Y / X}(y)$ $=F\left(Y_{t} \leq y\right)={ }_{F}\left(y_{t}-x_{t} \beta\right)$, where $\left\{x_{t}, t=1,2 \ldots, T\right\}$ denote a sequence of (row) k-vectors of a known design matrix. The $\theta^{\text {th }}$ regression quantile, $Q_{Y \mid X}(\theta), 0<\theta<1$ is defined as any solution to the minimization problem

$$
\begin{gathered}
\min _{\beta}\left[\theta \sum\left|y_{t}-x_{t} \beta\right|+(1-\theta) \sum\left|y_{t}-x_{t} \beta\right|\right] \\
\left\{t: Y_{t} \geq X_{t} \beta\right\} \quad\left\{t: Y_{t}<X_{t} \beta\right\}
\end{gathered}
$$

The resulting solution to equation 17 is denoted as $\beta_{\theta}$, from which we obtain the $\theta^{\text {th }}$ conditional quantile $Q_{Y / X}(\theta)={ }_{x} \beta_{\theta}$. In this paper $y_{t}$ can be INFLATION or MONEY variable and $x_{t}$ can be OPEN and MONEY variables in equations 14 to 16 .

\subsection{Meditation Analysis with a quantile equation}

An innovative method through combining meditation analysis and a quantile regression, which substitute equation 17 into equations 14 to 16 , can be described to equations 18 to 20 . It provides a useful supplement to the standard constant-parameter regression estimate (only one $\alpha$ or $\beta$ ) for studying all possible parameters (for all quantiles) vary across high dependent variable and low dependent variable. This method also leads to a more dynamic and complete understanding of what might really lie behind the stories of great effect or non-effect for openness on inflation. The quantile regression minimizes a weighted sum of the positive and negative error terms in equations 18 to 20 .

$$
\begin{aligned}
& \min _{b} \theta \sum \mid \text { INFLATION } b_{0}-b_{1} \text { OPEN } \mid+ \\
& (1-\theta) \Sigma \mid \text { INFLATION } b_{0}-b_{1} \text { OPEN } \mid \\
& \min _{c} \theta \sum\left|\operatorname{MONEY}_{\mathrm{t}}-c_{0}-c_{1} \mathrm{OPEN}_{\mathrm{t}}\right|+ \\
& (1-\theta) \sum \mid \text { MONEY }_{\mathrm{t}}-c_{0}-c_{1} \mathrm{OPEN}_{\mathrm{t}} \mid \\
& \min _{d} \theta \Sigma \mid \text { INFLATION } d_{0}-d_{1} \text { OPEN }-d_{2} \text { MONEX } \mathbf{t} \mid+ \\
& (1-\theta) \sum \mid \text { INFLATION }_{\mathrm{t}} d_{0}-d_{1} \text { OPEN }-d_{2} \text { MONEX } \mid
\end{aligned}
$$

\section{Result}

This study uses annual Taiwan data that covers the period 1961-2019. The data on GDP deflator (INFLATION), openness (OPEN), and money supply (MONEY) are compiled from the Taiwan Economic Journal. All variables are in logarithmic form except the openness variable. 
Before estimating equations 18 to 20, we use the Augmented Dickey-Fuller (ADF) unit root test to determine the order of integration of these three variables. The result demonstrates the unit root test results in levels and first differences with trend and intercept. The results show that we cannot reject the null hypothesis of the unit root for three variables in levels. However, we reject the null hypothesis of a unit root at the $1 \%$ significant level or better for the first-difference of these two variables. Based on the results from the ADF test, these three data series are integrated of order one.

Regarding the causal relationship between openness and inflation, and openness and money supply in equations 18 and 19, we demonstrate the causality test results in Table 1. The notation of $x \neq>y$ means that the variable $x$ does not affect the variable $y$.

We find out some remarkable results as follows. First, there is the causal relationship from openness to inflation by using traditional ordinary least square method (OLS). Second, through using a quantile approach, there also exists causality running from openness to inflation at lower distributions $(0.1$ to 0.5$)$ of inflation, but no causal relationship at higher distributions of inflation. In other word, there is no direct relationship between openness and inflation at higher distributions (0.6 to 0.9$)$ of inflation. Lastly, there exists causality running from openness to money supply by using traditional OLS method and at any distributions of inflation in Table 1. This result establishes the first stage of the mediated effect. It asserts that we only consider the mediated effect at lower distributions of inflation

The table 2 shows that $\mathrm{d}_{2}$ is significant both by using traditional OLS and a quantile approach at lower distribution of inflation in Equation 20, that is, the mediator variable MONEY relates to the dependent variable INFLATION. This result establishes the second stage of the mediated effect.

Moreover, through the OLS method, the variable OPEN should no longer relate to the dependent variable INFLATION after the mediator variable MONEY is controlled, such that $d_{1}$ is not significant in Equation 20. This condition shows that the relationship between OPEN and INFLATION examined under the first condition disappears when the mediated effect transmitted through MONEY is taken into account. This result evidences the complete mediation because of satisfying all four steps in equations 14 to 16 .

Third, through a quantile method, the variable OPEN should also no longer relate to the dependent variable INFLATION after the mediator variable MONEY is controlled at almost all distributions (except 0.3 and 0.5 distributions) of inflation in table 2. This condition shows that the relationship between OPEN and INFLATION examined under the first condition disappears when the mediated effect transmitted through MONEY is taken into account. This result evidences the complete mediation because of satisfying all four steps in equations 14 to 16 . However, the variable OPEN still relates to the dependent variable INFLATION at 0.3 and 0.5 distribution of inflation after the mediator variable MONEY is controlled, such that $\mathrm{d}_{1}$ is significant in Equation 20. This result indicates partial mediation because $\mathrm{d}_{1}$ in table 3 is still significant and is smaller than $b_{1}$ in table 2 .

\section{Conclusion}

A number of empirical literatures have examined the relationship between openness and inflation. Most research results found a direct negative effect of openness on inflation by using the ordinary least square method. However, in this paper we not only investigate if there is the direct relationship from openness to inflation in Taiwan, but also if there is the inflationary effects of increasing in the money supply with the openness of the Taiwan's economy. Moreover, in this study we use an innovative methodology which combines mediation analysis and a quantile regression that has allowed to obtain the full characterization of the conditional distribution of the dependent variable (inflation in our study), rather than its conditional mean only. That is, we provide a comprehensive 
picture of openness to inflation in Taiwan over the period of 1961 to 2019.

The results of the effects of openness on inflation are different from the previous results. Appling traditional ordinal least square method, we find trade openness affects inflation through the full mediation effect of money supply for the period of 1961-2019 and there is no direct relation between trade openness and inflation, which is totally different from the previous empirical findings. Moreover, by using a quantile regression and mediation analysis, we find trade openness affects inflation through the full mediation effect of money supply at almost all distributions of inflation. Therefore, these

Table 1

Results from OPEN to INFLATION and from OPEN to MONEY at different quantiles

\begin{tabular}{lllll}
\hline Quantile & $\begin{array}{c}\text { OPEN } \neq>\text { INFLATION } \\
\text { b1 }\end{array}$ & \multicolumn{2}{c}{ OPEN $\neq>$ MONEY } \\
c1 & & p-value \\
\hline 0.1 & $0.737^{*}$ & 0.000 & $0.532^{*}$ & 0.001 \\
0.2 & $0.760^{*}$ & 0.000 & $0.612^{*}$ & 0.000 \\
0.3 & $0.777^{*}$ & 0.000 & $0.809^{*}$ & 0.000 \\
0.4 & $0.798^{*}$ & 0.000 & $0.820^{*}$ & 0.000 \\
0.5 & $0.916^{*}$ & 0.000 & $0.879^{*}$ & 0.000 \\
0.6 & 0.298 & 0.289 & $0.591^{*}$ & 0.025 \\
0.7 & 0.197 & 0.450 & $0.668^{*}$ & 0.033 \\
0.8 & 0.072 & 0.763 & $0.461^{*}$ & 0.044 \\
0.9 & 0.032 & 0.882 & $0.504^{*}$ & 0.015 \\
OLS & $0.722^{*}$ & 0.000 & $0.762^{*}$ & 0.000 \\
& & & &
\end{tabular}

*Denotes significance at the $5 \%$,

Table 2

Results from OPEN and MONEY to INFLATION at different quantiles

\begin{tabular}{lcccc}
\hline Quantile & \multicolumn{2}{c}{ OPEN $\neq>$ INFLATION } \\
& $\mathrm{d}_{1}$ & \multicolumn{2}{c}{$\begin{array}{c}\text { MONEY } \\
\mathrm{d} \text {-value }\end{array}$} & $\begin{array}{c}\text { INFLATION } \\
\mathrm{p} \text {-value }\end{array}$ \\
\hline 0.1 & -0.018 & 0.913 & $0.972^{*}$ & 0000 \\
0.2 & -0.045 & 0.813 & $0.990^{*}$ & 0.000 \\
0.3 & -0.206 & $0.015^{*}$ & $1.189^{*}$ & 0.000 \\
0.4 & -0.154 & 0.111 & $1.153^{*}$ & 0.000 \\
0.5 & -0.193 & 0.043 & $1.150^{*}$ & 0.000 \\
0.6 & -0.076 & 0.566 & $0.969^{*}$ & 0.000 \\
0.7 & -0.030 & 0.856 & $0.981^{*}$ & 0.000 \\
0.8 & -0.018 & 0.947 & $0.933^{*}$ & 0.000 \\
0.9 & 0.054 & 0.720 & $0.674^{*}$ & 0.012
\end{tabular}



OLS
$-0.036$
0.494
$0.995^{*}$
0.000

*Denotes significance at the $5 \%$,

\section{References:}

[1] Baron, R. M. \& Kenny, D. A., The Moderator-Mediator Variable Distinction in Social Psychological Research: Conceptual, Strategic, and Statistical Considerations, Journal of Personality and Social Psychology, Vol.51, No.6, 1986, pp. 1173-1182

[2] Beltas, A. \& Jones, T., Money, inflation and causality in a financially repressed economy: Algeria, 1970-88, Applied Economics, Vol.25, 1993, pp. 473-480.

[3] Cheng, B. S., On the relationship between money and inflation in the United States: additional evidence, Applied Economics Letters, Vol.3, 1996, pp.549-552.

[4] Gruben, W. C. \& McLeod, D., Capital account liberalization and inflation, Economics Letters, Vol.77, 2002, pp. 221225.

[5] Gruben, W. C. \& McLeod, D., The openness-inflation puzzle revisited, Applied Economics Letters, Vol.11, 2004, pp.465-468.

[6] Hong, N. T. P. \& Linh, D. T. K., Effects of Earnings Management to Investor Decision Empirical Evidence in Vietnam Stock Market, WSEAS Transactions on Environment and Development, Vol.16, 2020, pp. 84-97

[7] Karras, G., Openness and the effects of monetary policy, Journal of International Money and Finance, Vol.18, 1999, pp.1326.

[8] Kim, M., \& Beladi, H., Is free trade deflationary, Economics Letters, Vol.89, 2005, pp.343-349.

[9] Koenker, R. \& Bassett, G.., Regression Quantile, Econometrica, Vol.46, 1978, pp33-49.

[10] Koenker, R. \& Hallock, K., Quantile regression, The Journal of Economic Perspectives, Vol.15, 2001, pp.143-156.

[11] Koenker, R., 2005. Quantile Regression, Econometric Society Monograph Series, Cambridge University Press, 2005.

[12] Lane, P. R., Inflation in open economics,
Journal of International Economics, Vol.42, 1997, pp.327-347.

[13] Parikh, A., Money supply and prices in Indonesia 1969-1980: an econometric investigation, Applied Economics, Vol.22, 1990, pp.1479-1494.

[14] Pesaran, M. H., The role of economic theory in modeling the long run, Economics Journal, Vol.107, 1997, pp.178-191.

[15] Pesaran, M. H., Shin, Y., \& Smith, R. J., Bounds testing approaches to the analysis of level relationships, Journal of Applied Econometrics, Vol.16, 2001, pp.289-326.

[16] Romer, D., Openness and inflation: theory and evidence, Quarterly Journal of Economics, Vol.108, 1993, pp.869-903.

[17] Sachsida A., Carneiro F. G., \& Loureiro, P .R. A., Dose greater trade openness reduce inflation? Further evidence using panel data techniques, Economics Letters, Vol.81, 2003, pp.315-319.

[18] Terra, C. T., Openness and inflation: a new assessment, Quarterly Journal of Economics, Vol.113, 1998, pp.641-648.

[19] Yang, Y. H., Causality between money, interest rates and prices in Taiwan: A multivariate time series analysis. Applied Economics, Vol.22, 1990, pp.1739-174

[20] Nebras Alattar, Jabar Yousif, Moosa Jaffer, S. A. Aljunid,Neural and Mathematical Predicting Models for Particulate Matter Impact on Human Health in Oman, WSEAS Transactions on Environment and Development, Volume 15,2019 , pp. $578-585$ 